\title{
Hand hygiene improvement program in the Canary Islands, Spain
}

\author{
J Molina ${ }^{1 *}$, P Garcia ${ }^{2}$ \\ From International Conference on Prevention \& Infection Control (ICPIC 2011) \\ Geneva, Switzerland. 29 June - 2 July 2011
}

\section{Introduction / objectives}

To describe the evaluation of a coordinate campaign on hand hygiene $(\mathrm{HH})$ improvement in the Healthcare System in the Canary Islands after the first year of implementation.

\section{Methods \\ Setting}

Ten public healthcare hospitals. A core team with a plan for implementation was set at the beginning.

\section{Intervention}

Implementation of the WHO multimodal strategy for improving $\mathrm{HH}$.

\section{Measures}

Direct observation of hand hygiene for 1 and 2 moments (before patient contact and before aseptic task) in emergency and intensive care units and consumption of alcohol-based products for hand rub (liters / 1000 patient-days) every six months in two sixmonth's period. Training was performed in each facility.

\section{Results}

Alcohol-based hand rub products were made available at each centre. 1730 dispensers accounted for the 3861 available beds $(44,8 \%)$. Seven out of ten hospitals implemented training about $\mathrm{HH}$, but just four centers trained about the concept of "My Five Moments for Hand Hygiene". Medical doctors had the lowest level of attendance.

Eight out of ten hospitals have performed direct observation of compliance. Overall rate: $33,3 \%,(29,7 \%$ the first period; $35,9 \%$ for the second $(p<0,05))$. Alcoholbased products were used in $49,6 \%$ of occasions in which actions of $\mathrm{HH}$ occurred. The consumption ranged from 18,1 to 39,2 L/ 1000 patient-days (average 27,3 $\mathrm{mL} / 1000$ patient-days). Reminders were used and a local guide was performed and released.

The core team met in four occasions. Each facility was required to address a clear plan of activities for 5 may 2010. All centers have had registered to the 2009 WHO initiative "Save Lives: Clean your hands".

\section{Conclusion}

A clear improvement in $\mathrm{HH}$ practices was achieved. In order to get sustainability, new activities including clear commitment of leaders, patient involvement, and a system for ensuring $\mathrm{HCW}$ training are required.

\section{Disclosure of interest}

None declared.

\section{Author details \\ ${ }^{1}$ Servicio Canario de la Salud, Las Palmas, Spain. ${ }^{2}$ Servicio Canario de la Salud, Tenerife, Spain.}

Published: 29 June 2011

doi:10.1186/1753-6561-5-S6-P126

Cite this article as: Molina and Garcia: Hand hygiene improvement program in the Canary Islands, Spain. BMC Proceedings 2011 5(Suppl 6): P126.

${ }^{1}$ Servicio Canario de la Salud, Las Palmas, Spain

Full list of author information is available at the end of the article

(c) 2011 Molina and Garcia; licensee BioMed Central Ltd. This is an open access article distributed under the terms of the Creative 